\title{
TELEONOMÍA Y FUNCIÓN BIOLÓGICA. UNA INVESTIGACIÓN SOBRE LAS RAÍCES Y LAS VIRTUALIDADES DE LA TELEONOMÍA SEGÚN KONRAD LORENZ
}

\author{
Laura Durieux Montoya \\ Universidad de Málaga
}

\begin{abstract}
Resumen: Esta investigación trata de la cosmovisión reflexiva y crítica sobre el papel de la finalidad en la biología elaboradas por Konrad Lorenz. Se trata de una investigación en filosofía y no en biología, por lo que las principales aportaciones de Lorenz a la Etología se insertan en el marco teórico definido por los conceptos de (i.) organismo en Kant, (ii.) evolución adaptativa en Darwin y (iii.) recuperación de la finalidad como teleonomía. Lorenz rechaza la teleología de raigambre aristotélica, y propone un modelo teórico en biología de raíces kantianas y hartmantianas. Se trata de un modelo explicativo en biología. Mi intención en esta investigación radica en explorar las raíces y las virtualidades del modelo explicativo de la finalidad en biología propuesto por el etólogo austriaco.

Palabras clave: Konrad Lorenz; Finalidad; Teleonomía; Evolución; Etología; Aristóteles; Kant; Hartman; Darwin; Manfred Eigen

TELEONOMY AND BIOLOGICAL FUNCTION. AN INVESTIGATION ON THE ROOTS AND VIRTUALITIES OF TELEONOMY ACCORDING TO KONRAD LORENZ
\end{abstract}

Abstract: This paper focusses on the reflective and critical worldview on the role of finality in biology elaborated by Konrad Lorenz. This is a research in philosophy and not in biology, so the main contributions of Lorenz to Ethology are inserted in the theoretical framework defined by the concepts of (i.) Organism according to Kant (ii.) Adaptive evolution according to Darwin. (iii.) and the recovery of finality as teleonomy. Lorenz rejects the teleology of Aristotelian roots and, proposing instead of it a theoretical model in biology of Kantian and Hartmantian roots. It is an explanatory model in biology. My intention with this 


\section{Laura Durieux Montoya}

research is to explore the roots and potentialities of the explanatory model of the purpose in Biology proposed by the Austrian ethologist.

Keywords: Konrad Lorenz; Finality; Teleonomy; Evolution; Ethology; Aristotle; Kant; Hartman; Darwin; Manfred Eigen.

Recibido: 26 de abril de 2021

Aceptado: 26 de mayo de 2021

DOI 10.24310/NATyLIB.2021.vi15.12427

«Si pudiera poner en uno de los platillos de una balanza todo lo que gané en percepción en estas horas de meditación ante el acuario y lo que me enseñaron los libros, a buen seguro que el segundo platillo se elevaría hasta las nubes». ${ }^{1}$

\section{Introducción}

El biólogo austriaco Konrad Lorenz (1903-1989) recibió el premio Nobel de Medicina en 1973. Este reconocimiento le fue otorgado por sus profundos conocimientos en Historia Natural y Etología. ${ }^{2}$ Se puede afirmar que Lorenz es el padre — junto al biólogo holandés Niko Tinbergen — de esta última di-

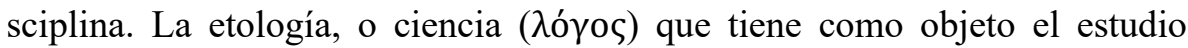
comparado del comportamiento (o el carácter: $\tilde{\eta} \theta$ os) animal.

Lorenz se diferencia de otros etólogos en que producen su obra en el periodo que podríamos calificar de prehistoria de la etología. Se trata de la etapa que media entre la publicación La expresión de las emociones en los animales

${ }^{1}$ Lorenz, K., Hablaba con las bestias, los peces y los pájaros, Tusquets, Barcelona, 2017 (2 edic.)

${ }^{2}$ Resulta impresionante y esclarecedor de los motivos que condujeron a la nominación de Lorenz para el premio nobel, ojear el índice de sus Fundamentos de la etología. Comienza exponiendo lo diferencial de la metodología en las ciencias biológicas, realiza una profunda crítica a los métodos no sistémicos en biología, y expone sus investigaciones sobre los mecanismos neurales y genéticos del comportamiento filogenéticamente programados. Sólo en su tercera parte, Lorenz se centra en la modificación adaptativa del comportamiento. Cfr.: Lorenz, K., Fundamentos de la etología. Estudio comparado de las conductas, Paidós, Barcelona, 2016 ( $6^{\mathrm{a}}$ reimpresión). 
y los hombres de Darwin, y su propia obra o la de Tinbergen. Etólogos como George Romanes se vieron pronto desprestigiados por su falta de rigor científico. Otros pioneros como Charles O. Whitman, Oskar Heinroth, Wallace Craig y Julian Huxley, ${ }^{3}$ contribuyeron a fortalecer la etología, construyendo por ejemplo los célebres etogramas. Parecería que Lorenz, cuando escribe la cita que abre este trabajo, tiene en la mente todo el cúmulo de registros sobre la conducta animal recogida en estos catálogos. Y, sin embargo, la observación empírica y el trato asiduo con los animales que estudiaba le permitieron

[...] algunos de los hallazgos más relevantes en la base de la etología [...]. Conceptos como la jerarquía, la ritualización de las conductas de lucha y cortejo, la impronta o "proceso de fijación irreversible", con su periodo crítico, el vínculo social, la respuesta innata versus el aprendizaje, el valor de supervivencia del comportamiento (revelando la omnipresencia de la selección natural y el proceso evolutivo), la inhibición del ataque mortal, las conductas de desplazamiento). ${ }^{4}$

Estos descubrimientos cambiaron la historia de la biología e influyeron decisivamente en la Antropología filosófica, disciplina en la que se inserta esta investigación. Estos hallazgos de Lorenz están presentes en este trabajo cuyo cometido no son las aportaciones biológicas de Lorenz, sino su encuadre en una cosmovisión reflexiva y crítica del papel de la finalidad en la biología. Cuando explore las aportaciones de Lorenz a la biología, mi finalidad no será meramente la exposición de sus contribuciones a la biología como ciencia empírica. Eso sería hacer de este trabajo una investigación biológica. Mi cometido, en cambio, radica en investigar en esos conceptos la aportación de Lorenz al conocimiento de la relación entre selección y adaptación teleonómica.

Con su concepto de teleonomía, Lorenz rechaza la teleología de raigambre aristotélica, y propone un modelo teórico en biología de raíces kantianas y

${ }^{3}$ Cfr.: Lorenz, K., Evolución y modificación de la conducta, Siglo XXI editores, Madrid, 1971, capítulo 5: «Crítica a la actitud de los etólogos modernos», pp. 27-79.

${ }^{4}$ Delibes de Castro, M., «Queríamos ser Konrad Lorenz»en Lorenz, K., Hablaba con las bestias..., op. cit., p. 15. 
hartmantianas. Se trata de un modelo explicativo en biología. Como ha señalado Antonio Diéguez «hay muchos tipos de modelos y no es de extrañar, por tanto, que puedan proporcionar explicaciones de los fenómenos de formas muy diversas. Si se puede señalar un rasgo común a todos estos modos diferentes de explicar, es el hecho de que los modelos nos ofrecen una mejor comprensión de los fenómenos». ${ }^{5} \mathrm{Mi}$ intención en esta investigación radica en explorar las raíces y las virtualidades del modelo del etólogo austriaco. El rasgo particular del modelo teleonómico radica, como bien ha expresado Miquel de Renzi, en admitir que si «la funcionalidad existe, no deriva de un propósito». ${ }^{6}$ Es decir, Lorenz admitiría como biológico el concepto de función, pero no le llevaría a ningún compromiso ontológico con la teleología clásica, sino con el concepto kantiano de organismo.

\section{Finalidad y causalidad en la naturaleza según Lorenz}

\section{II.1. El encuentro de Lorenz con Kant}

(Kant) no es, por tanto, "materialista", en aquel sentido ideológico-moral con que suelen criticarlo los teólogos, sino que constituye el servicio más intenso a la finalidad última de todo acontecer orgánico. ${ }^{7}$

Habitualmente se señala que la relación de Lorenz con la filosofía está estrechamente vinculada a la figura de Inmanuel Kant. No en vano fue el filósofo que más leyó, y que con más fuerza interpretó y criticó. ${ }^{8}$ En un pasaje de sus Fundamento de etología, Lorenz confiesa la relevancia filosófica de la filosofía trascendental kantiana.

\footnotetext{
${ }^{5}$ Dieguez, A., «La función explicativa de los modelos en biología» en Diéguez A., (ed.) Filosofia actual de la biología, Contrastes, suplemento XVIII (2013), p. 41.

${ }^{6}$ Renzi, M., «La funcionalidad, si existe, no deriva de un propósito. Una argumentación desde la biomorfodinámica y la evo-devo» en Ibid., p. 143.

${ }^{7}$ Lorenz, K., Fundamentos de la etología..., p. 45, 47.

${ }^{8}$ Lorenz, K., «Kant's Doctrine Of The A Priori In The Light Of Contemporary Biology», en H. Plotkin (Ed.), Learning, development and culture, John Wiley and Son, Chichester, pp. 121143. 
Desde luego, al estudiar un sistema viviente complejo hay que formular simultáneamente las preguntas de finalidad y de causalidad [...] La aspiración a "buscar las causas universales hasta donde nos sea posible y de seguir la cadena de éstas hasta donde no se interrumpa" (Kant) no es, por tanto, "materialista", en aquel sentido ideológico-moral con que suelen criticarlo los teólogos, sino que constituye el servicio más intenso a la finalidad última de todo acontecer orgánico al conferirnos, donde ha tenido éxito, el poder para intervenir ayudando y regulando donde haya valores en peligro y donde el observador meramente teleológico sólo puede cruzarse de brazos y llorar pasivo la pérdida de la totalidad que está desintegrándose. ${ }^{9}$

Lorenz se muestra como un kantiano que admitiría meramente la noción de una finalidad formal o subjetiva en la naturaleza. La estructura y el comportamiento de los organismos vivos parece diseñada para un fin. Lorenz piensa, al igual que Kant, que cuando hablamos de una finalidad objetiva en la naturaleza, estamos trasponiendo el modo de ser de las acciones humanas, que se conducen de acuerdo con objetivos, planes, diseños, fines, etc., al ámbito de la naturaleza. Pero que esta trasposición es ilegítima. La reflexión científica ha de proceder buscando las causas, puesto que no es competente para dirimir si los organismos vivos fueron «diseñados» inteligentemente, si hay un designio, detrás de ellos. En ese caso, la «idea», o «proyecto» de cada ser vivo, sería anterior a su formación. Pues bien, Kant, en la Crítica del Juicio dejó escrito que:

[...] es absolutamente contrario a la naturaleza de las causas físico-mecánicas, que el todo sea la causa de la posibilidad de la causalidad de las partes, ya que más bien, éstas (las partes) tienen que estar dadas previamente para concebir a partir de ellas la posibilidad de un todo; siendo la representación particular de un todo, que precede a la posibilidad de las partes, una mera idea ${ }^{10}$

Parece que el científico y el filósofo consideran la misma realidad desde dos ángulos completamente opuestos. El científico ha de considerar las leyes entre causas meramente mecánicas. Estudia para ello las partes y su dinámica.

${ }^{9}$ Lorenz, K., Fundamentos de la etología..., p. 45, 47.

${ }^{10}$ Kant, I., Ak.-Ausg. XX, 236. 
Pero la consideración teleológica de la naturaleza, estudia las partes desde un todo previo a ellas. Pero ese todo, o finalidad diseñada que antecedería a las partes, sólo puede ser una idea. Carecería de estatuto real, solamente pensado. Podemos reflexionar mucho sobre fines, pero el concepto de fin no determina en modo alguno la estructura y dinámica de los objetos naturales. Lorenz introduce un ejemplo en el texto anteriormente citado. Y es que por mucho que reflexionemos sobre la finalidad que teníamos al trasladarnos a otra ciudad, y la finalidad que puede tener para nuestros propósitos el vehículo en que nos trasladamos, jamás podremos por ello, arreglar la avería que ha sufrido ese vehículo. Sólo conociendo las leyes y causas mecánicas podremos hacerlo.

Pero Lorenz, igual que Kant, no desdeña las preguntas por la finalidad, en favor de las preguntas por la causalidad. Según él «hay que formularlas simultáneamente». ${ }^{11}$ Por lo tanto, al científico no le es legítimo esquivar la pregunta por la finalidad de los sistemas vivientes complejos. Kant había señalado que el entendimiento se ocupa de las causas mecánicas, y que la razón forzosamente ha de situarse en la perspectiva teleológica. ¿Cómo unificar ambas perspectivas, las que nos proporcionan sendas facultades? ¿Puede el científico hacerlo?

\section{II.2. El encuentro de Lorenz, con Nicolai Hartmann}

Cuando se conocen en alguna medida las reglas de juego según las cuales procede el crecimiento del árbol genealógico de la vida, deja de sorprender el hecho de que en la construcción de seres vivientes, al lado de soluciones constructivas en verdad geniales, se encuentren otras que cualquier técnico humano podría mejorar sustancialmente. ${ }^{12}$

En las primeras páginas de sus Fundamentos de etología, al considerar la metodología del pensamiento biológico, Lorenz sienta claramente que el biólogo, a diferencia del físico, del químico o del geólogo «se ve obligado a

${ }^{11}$ Lorenz, K., Fundamentos de la etología..., p. 45.

12 Ibid., p. 39. 
formular la cuestión de la finalidad. En el cosmos sólo hay procesos determinados por una finalidad en la esfera de lo orgánico». ${ }^{13}$

El biólogo, y en particular el etólogo, está obligado a formular la validez o invalidez de la finalidad. Para él, a diferencia de científicos que tratan otras ramas del saber, la finalidad de las acciones de los seres vivos. Y esto es particularmente importante en etología. Lorenz explica, siguiendo a Nicolai Hartmann que la etología se encuentra con la finalidad al considerar (i.) la anticipación del comportamiento a realizar; (ii.) la selección de los medios; (iii.) la realización de esa acción con esos medios. ${ }^{14}$

Lorenz realiza sus investigaciones en un mundo científico en el que se han realizado importantísimas contribuciones a la bioquímica, la morfogénesis y la conducta apetitiva animal. Y es por conocer las aportaciones de estas ciencias por lo que se enfrenta a Hartmann. Para este último la finalidad siempre exige una conciencia que anticipe, seleccione medios y realice finalmente la acción. Para Lorenz en cambio, se pueden observar fenómenos teleológicos en seres que carecen de conciencia. Y por ello a nivel bioquímico, tisular y botánico. Aquí radica la primera diferencia entre Hartmann y Lorenz. Mientras que Hartmann reserva la finalidad para los seres vivos dotados de conciencia, Lorenz que en esto es, curiosamente más kantiano que Hartmann, extiende la finalidad, al menos formalmente, a lo que los clásicos llamaron vida vegetativa en todos sus niveles.

A nivel embriológico Lorenz descubre la teleología de la programación genética y de la selección de medios y estrategias por el embrión para realizar su proceso adecuadamente:

La "programación" prevista en el genotipo anticipa como finalidad la génesis de un nuevo organismo; con una selección bastante variable y adaptable de los medios ofrecidos por el ambiente, tal objetivo se logra en una sucesión estrictamente causal de fases evolutivas. Es evidente que ese proceso se corresponde por entero con la acción conjunta de los tres actos postulada por Hartmann. Lo mismo es válido para los fenómenos un tanto complejos de la conducta apetitiva a través de la cual el animal consigue un efecto final con un sentido preservador de la especie

${ }^{13}$ Ibid., 36.

${ }^{14}$ Cfr.: Ibidem. 


\section{Luis Fernández Navarro}

que también está programado en el genotipo. Por más que fenómenos tales como la embriogénesis y la conducta con toda seguridad no los gobierne una conciencia individual previsora, sino que se desarrolla en un nivel muy inferior del acontecer orgánico, debemos considerarlos ciertamente como orientados hacia un objetivo o "fin determinados". ${ }^{15}$

La rectificación a Hartmann no reside en una mera constatación empírica de procesos embriológicos, o de cualquier otra fisiología. Resulta curioso que al desarrollo de un organismo lo denomine evolución. Y a las fases de dicho desarrollo «fases evolutivas». Parece como si Lorenz desligase la teleología que él observa en la naturaleza de cualquier compromiso ontológico con un diseño inteligente. La evolución ha dado lugar por sí, sin tener que recurrir el biólogo a un Dios inteligente o una armonía preestablecida, a conductas teleológicas en todos los niveles de lo orgánico.

Si Lorenz, y con él todo el pensamiento biológico, se ve obligado a admitir la teleología en la naturaleza, no por ello se siente obligado a admitir una inteligencia perfectísima que haya diseñado previamente la mecánica genética, o la morfogénesis. Y esto porque:

A cada paso el estudioso de la historia comparada de las especies se encuentra con "errores" de la evolución, con construcciones equivocadas y de una falta de perspicacia que nos parecería imposible en un constructor humano. ${ }^{16}$

Pues bien, esto lleva a Lorenz a dar un paso más. La teleología se puede admitir en las acciones de los organismos individualmente considerados, pero no en la línea filogenética. No hay una orden que guíe la evolución en su conjunto. Del mismo modo que el biólogo no tiene un compromiso ontológico con un diseñador inteligente, y eso se constata por los "errores", tampoco ese diseñador ha establecido un orden y una dirección entre los diversos seres vivos considerados evolutivamente. Por eso afirma que «la evolución es todo lo

\footnotetext{
${ }^{15}$ Ibid., p. 37

${ }^{16}$ Ibid., p. 38 .
} 
contrario de un acontecer dirigido a un fin». ${ }^{17}$ La evolución es un hecho completamente casual. Pero esto nos lleva al tema de la recepción de Darwin por Lorenz.

\section{II.3. La irrupción de Darwin en los estudios psicológicos}

Konrad Lorenz es un biólogo evolucionista convencido. Dedicó gran parte de sus investigaciones a estudios filogenéticos. Partía siempre de la reconstrucción de árboles genealógicos de las especies cuyo comportamiento estudiaba, y dio gran importancia a los testimonios fósiles. Por eso, afirmará contundentemente que

[...] la teoría de la evolución no es "teoría", sino historia auténtica e incomparablemente más segura que la historia de la humanidad transmitida por todos los bienes culturales y la palabra escrita. ${ }^{18}$

La teoría de la evolución le permitirá a Lorenz explicar la transmisión filogenética de determinados mecanismos fisiológicos que observamos en el comportamiento animal. Es evidente que Lorenz no se queda en los estudios de genética, sino que su contribución más significativa fue el estudio de la modificación adaptativa del comportamiento. Aquí la genética se abre al aprendizaje. Pero siempre desde una perspectiva evolucionista.

Cuando Lorenz define el objeto material y formal de la etología, lo hace en explícita referencia a las teorías darwinianas.

La etología, o estudio comparado del comportamiento, es fácil de definir: consiste en aplicar al comportamiento de los animales y de los hombres todos aquellos

\footnotetext{
${ }^{17}$ Ibidem.

${ }^{18}$ Lorenz, K., Fundamentos de la etología ..., p. 91. Según Theodora J. Kalikow la importancia de la teoría de la evolución en Lorenz es tal, que se podría entresacar de sus obras toda una epistemología evolutiva. Cfr.: Kalikow, Th. J., «Konrad Lorenz as Evolutionary Epistemologist: The Problem of Intentionality» en Shimony A., Nails, D. (eds.), Naturalistic Epistemology. Boston Studies in the Philosophy of Science, Springer, Dordrecth, vol. 100, pp. 119-144.
} 
interrogantes y métodos ya de uso corriente y natural en todos los demás campos de la biología después de Charles Darwin. ${ }^{19}$

La etología es una disciplina que estudia comparadamente el comportamiento animal. Ese es su objeto material. Es por tanto una disciplina que se inscribe dentro de las investigaciones biológicas y psicológicas. La psicología también ha de explicar el comportamiento y los dinamismos psíquicos que le subyacen. La novedad de Lorenz estriba en llevar la teoría de la evolución a las ciencias psicológicas del comportamiento. ${ }^{20}$ Un cometido, que Lorenz reconoció que no fue nada fácil por cuestiones ideológicas que definían a los pioneros de la psicología. ${ }^{21}$

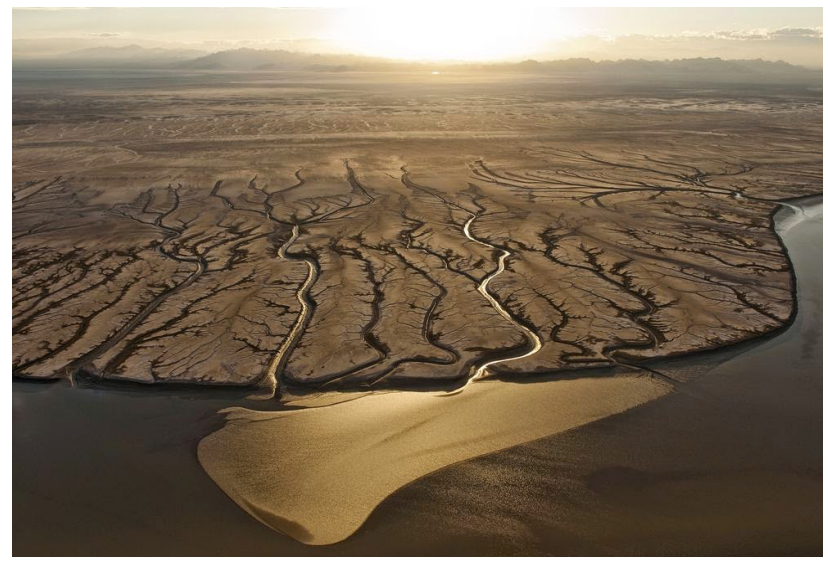

de expresarse induce a error. ${ }^{22}$

Pues bien, según Lorenz, es preciso despejar algunos malentendidos sobre la teoría de la evolución.

Formalmente es correcto decir que la evolución sólo procede según los principios de la ciega casualidad y la eliminación de lo incapaz de existir, y sin embargo este modo

Si las líneas filogenéticas no han sido diseñadas inteligentemente, entonces parecería que son por completo azarosas, casuales, y ciegas. Lorenz no está comprometido a admitir ningún relojero del proceso evolutivo. Pero tampoco a admitir que si hubiera un relojero sería ciego, como dice Dawkins. Dawkins piensa que, si hubiese un relojero del cosmos, este sería bastante miope, no ve de lejos, no puede planificar a largo plazo. La vida y su complejidad es la suma

\footnotetext{
${ }^{19}$ Ibid., p. 17.

${ }^{20}$ Ibidem.

${ }^{21}$ Ibidem.

22 Ibid., p. 39.
} 
de un sinnúmero de modificaciones azarosas. ${ }^{23}$ La historia de la vida no es la historia de una serie de adaptaciones óptimas al ambiente. Rara vez se dan este tipo de adaptaciones. Las adaptaciones seleccionadas suelen ser mejores que otras, pero no las mejores. Como comenta el propio Lorenz siguiendo a Eigen, las mutaciones genéticas que son beneficiosas para la supervivencia de un organismo son sumamente improbables (del orden de $10^{-8}$ ). ${ }^{24}$ Por eso el árbol de la vida se parece más a las tortuosas ramificaciones de un gran río en su delta, que al diseño de encauzamiento de un río por un equipo de ingenieros. El curso del río, dirá Lorenz está determinado por millones de influencias causales. Lo mismo sucede con el río de la vida. Ha evolucionado según lo que permitían un número ingente de causas.

En el texto anterior se afirmaba que es engañoso admitir que la evolución está regida por dos principios: el ciego azar y la selección del más fuerte. Y es engañoso porque para Lorenz, siguiendo a Manfred Eigen, el azar está domésticado. Para Eigen, y su teoría de los hiperciclos, la evolución está regida por el segundo principio de la termodinámica. La vida no se desarrolla al margen de las leyes fundamentales de la física. Por lo que la vida no es completamente azarosa. ${ }^{25}$ Además, Lorenz cita los trabajos de Eigen en genética molecular sobre la efectividad de la selección natural a nivel molecular y en la biogénesis. $^{26}$

\section{II.4. Función biológica y teleonomía}

Nunca la estructura total de un organismo es igual a una obra humana diseñada por un constructor largamente previsor según un único plano, sino que se parece mucho más a la casa que un colono ha construido para sí: primero levanta una simple cabaña para protegerse contra el viento y la lluvia, agrandándola a medida que aumentan posesiones y familia. La cabaña inicial no es derruida, sino que se convierte en trastero, y casi todos los cuartos de la construcción total pierden su función original en el curso de la evolución. Los restos históricos reconocibles

${ }^{23}$ Dawkins, R., El relojero ciego, RBA, Barcelona, 2004, capítulos 1 y 2.

${ }^{24}$ Ibid., p. 39.

${ }^{25}$ Cfr.: Eigen, M. \& Schuster, R. P, The Hypercycle. A principle of natural self organization, Springer-Verlag, Berlin, 1979

${ }^{26}$ Lorenz, K., Fundamentos de la etología, ..., p. 38. 
como tales se conservan por el mismo hecho que determinó que la construcción nunca pudiera ser completamente derribada ni planificada de nuevo: ello era imposible precisamente porque estuvo habitada todo el tiempo y sometida a un uso intenso. $^{27}$

Lorenz, a la hora de explicar el comportamiento animal, se encontró con tres hipótesis fundamentales, y rivales: (i.) la teoría de la evolución; (ii.) la creencia religiosa en un Creador que hubiese dispuesto con suma inteligencia la adaptación de los animales a su entorno; y (iii.) la teoría biológica sostenida por Uexküll de una armonía preestablecida entre el sistema orgánico y su medio entorno.

Mucho tiempo antes de que se descubrieran las causas principales de toda adaptación, es decir, la variabilidad hereditaria y la selección natural, a los investigadores de sistemas orgánicos les llamó la atención el hecho de que la estructura de estos sistemas estuviera dispuesta de una manera específica y, en general, asombrosa, para conservar la vida del individuo, de sus descendientes y, con ello, de su especie. Las personas que creían en un acto de creación único explicaban esta funcionalidad conservadora de la especie a partir de la especie a partir de la sabiduría del Creador, o como Jakob von Uexküll, que rechazaba la idea de la evolución, a partir de una armonía preestablecida entre el organismo y su ambiente. Quien pueda contentarse con estas explicaciones se ahorra el planteamiento de muchos problemas complejos, aunque a costa de tener que cerrar los ojos ante determinados fenómenos: las numerosas faltas de funcionalidad en la construcción de los seres vivientes. ${ }^{28}$

Lorenz no era un evolucionista ingenuo. Su aceptación del evolucionismo es crítica, muy reflexiva. Si creacionistas y teóricos de la biología como Uexküll señalan, como ya lo hizo Platón en el mito de Prometeo y Epimeteo, el fenómeno de la asombrosa adaptación del organismo animal al medio, y por lo tanto la especialización de sus órganos a dicho ecosistema, Lorenz como evolucionista opone a ese hecho, otro: el de la falta de funcionalidad de algunas estructuras biológicas. No todo en el organismo animal está adaptado al

${ }^{27}$ Ibid., p. 41

${ }^{28}$ Ibid., p. 36 . 
ambiente, ni todos los animales están especializados anatómica y comportamentalmente al ambiente que les rodea. Las mutaciones son azarosas, y eso da lugar a variantes genéticas que no pueden sobrevivir en un ambiente. Esta es la base, el fundamento fáctico, de la teoría de la evolución.

En la dualidad forma-función, creacionistas y partidarios de la armonía preestablecida entre sistema biológico-medio ambiente, veían una correlación exacta. Platón, hace que Epimeteo diseñe teleológicamente las diferentes estructuras del organismo de los diversos seres vivos. Todas ellas tienen una función desde su diseño inteligente. Epimeteo tiene un propósito, una intención, y prevé las dificultades que el ambiente impondrá a los organismos en él. Pero, como puso de relieve Jacques Monod en El azar y la necesidad, en la morfogénesis viviente los procesos teleológicos sólo tienen sentido retrospectivamente. Los seres vivos se generan, mutan y transmiten a su herencia mutaciones en su diseño estructural, sin prever los cambios en el ambiente. Será la competición con el ambiente y con otros congéneres, la que elimine las estructuras no funcionales. Pero en modo alguno la funcionalidad está prevista. Es un resultado, no una intención prediseñada. Pero que sea un resultado, no anula el hecho de que los seres vivos se distinguen efectivamente, de todas las demás estructuras naturales, por su teleonomía. ${ }^{29}$

Teleología y teleonomía se distinguen como la astrología de la astronomía. ${ }^{30}$ «Teleonomía» es un concepto puesto en circulación por el biólogo británico Colin Pittendrigh, al tratar de la adaptación biológica.

Actualmente el concepto de adaptación está comenzando a disfrutar de una creciente respetabilidad por las siguientes razones. Es visto como menos que perfecto; la selección natural se entiende mejor; y el físico o ingeniero que construye autómatas que buscan finalidades ha santificado el uso de la jerga teleológica. Parece poco afortunado que el término "teleología" deba resucitarse, lo que sería, pienso un abuso. La larga confusión biológica podría eliminarse mejor si los sistemas dirigidos-a-fin se describiesen con algún otro término, como "teleonómico", para enfatizar que el reconocimiento y la descripción de la dirección-a-fines no acarrea

${ }^{29}$ Monod, J., El azar y la necesidad. Ensayo sobre la filosofia natural de la biología moderna, Tusquets, Barcelona, 2016, p. 22.

${ }^{30}$ Cfr.: Lorenz, K., Fundamentos de la etología..., p. 42. 
el compromiso con la teleología aristotélica como un principio causal eficiente (sic). ${ }^{31}$

Lorenz, al igual que Pittendrigh acepta la idea de teleonomía. No hay ningún compromiso teleológico en admitir la idea de teleonomía. Efectivamente, teleónomos y teleólogos admiten que los seres vivos son sistemas orientados a fines. En esto son estrictamente kantianos. Pero en lo que se diferencian es en no admitir un diseño inteligente previo a los seres vivos. Éstos no están diseñados previamente a su existencia. Los seres vivos no son seres artificiales. Su carácter orgánico es fruto de una larga historia evolutiva ciega.

Todo rasgo estructural de un sistema vivo que haya sido objeto de una adaptación selectiva es, para Lorenz, teleonómico. Y en esto Lorenz ve una diferencia entre los rasgos heredados por animales criados por el ser humano y animales en estado salvaje. Un rasgo como el color del plumaje o del pelo puede ser indiferente y casual entre los individuos nacidos en un criadero artificial. Pero ese rasgo, entre animales en estado salvaje, generalmente será teleonómico: favorecerá el mimetismo o la visibilidad del animal, etcétera. La especie se preserva merced a estos rasgos, por los que el animal se adapta al ambiente.

Lorenz resume su parecer en la siguiente ecuación:

Cuanto más compleja e improbable una combinación de rasgos, tanto más segura la conclusión de una conexión entre función y selección, tanto más sencilla la respuesta a la pregunta del "para qué". ${ }^{2}$

La aparición de rasgos estructurales muy diferentes y, muy heterogéneos entre sí, incluso con aparentes desventajas adaptativas, implican para Lorenz, que la selección ha actuado afinando una función biológica, y que por ello esos rasgos son teleonómicos. Según Lorenz estos rasgos han de tener una

\footnotetext{
${ }^{31}$ Pittendrigh, C., "Adaptation, Natural Selection, and Behavior", in Anne Roe and George Gaylord Simpson (eds.), Behavior and Evolution (New Haven, 1958), 390-416 http://www.informationphilosopher.com/solutions/scientists/pittendrigh/

${ }^{32}$ Lorenz, K., Fundamentos de la etología, cit., p. 42. 
función: bien para adaptarse a las características del medio, bien para la reproducción, bien para la predación o para el combate. Pero función y finalidad están estrechamente emparentadas y siempre que se observan unos rasgos estructurales, según Lorenz, hay que presuponer la función de esos rasgos, aunque aparentemente no la comprendamos. No obstante, la función es seleccionada, pero no propuesta. La función es siempre un rasgo adaptativo, que como dice Miquel de Renzi «surge a través del desarrollo, que tiene una causalidad propia, sin propósito con respecto al organismo adulto. El desarrollo está canalizado y sujeto a limitaciones (constraints); por ello, no se alcanzan óptimos adaptativos en general». ${ }^{33}$ Resulta curioso que Lorenz hubiese llegado ya en 1978 a los mismos resultados que Renzi propone desde la biomorfodinámica y la evo-devo.

No obstante, Lorenz siempre se muestra receloso sobre la extensión de la finalidad de una función a la supervivencia de la especie en su conjunto. Pone un ejemplo claro y difícilmente refutable. Las alas de un pavo real tienen una función reproductiva evidente. Pero cuanto mayor sea esta función más visible es el pavo real también para sus predadores. Por eso concluye Lorenz que «la forma viviente y función son un compromiso entre varias clases de presión selectiva». ${ }^{34} \mathrm{El}$ éxito reproductivo y él éxito en la supervivencia frente a posibles predadores presionan en direcciones opuestas en este caso. Y por ello, lo que puede ser ventajoso reproductivamente no tiene porque serlo frente a los predadores. Se trata de un diseño con una finalidad evidente, pero esa finalidad no resuelve todos los problemas que el individuo y la especie se le presentan. Lo que soluciona un problema, puede muy bien ocasionar otros. Otro ejemplo que pone Lorenz es el tamaño de la cornamenta en los ciervos. El tamaño de ésta es directamente proporcional a la atracción que van a prestar las hembras y a su receptividad sexual. Pero el problema es que la teleonomía reproductiva del tamaño de la cornamenta, resolviendo un problema, plantea otros problemas muy agudos respecto de la capacidad de la osamenta del cráneo y de la musculatura del cuello para soportar el crecimiento de estas cornamentas.

${ }^{33}$ Renzi, Miquel de, «La funcionalidad, si existe, no deriva de un propósito...» op. cit., p. 143.

${ }^{34}$ Lorenz, K., Fundamentos de la etología, cit., p. 43. 
Por todo ello, Lorenz concluye que:

La pregunta teleonómica del "para qué" obtiene, pues, a menudo unas respuestas que presuponen unos fines bastante modestos e incluso nocivos para la preservación de la especie. ${ }^{35}$

Cuando Lorenz habla del placer con que las aves vuelan, y juegan a realizar picados, giros, y todo tipo de acrobacias, señala que:

«El placer de la función está teleonómicamente incorporado al proceso de aprendizaje que torna estos movimientos de destreza cada vez más fluidos, elegantes y economizadores de energía. La mejor forma de alcanzar esta meta que en sí está fijada con un criterio de utilidad es que se establezcan relaciones armónicas entre las partes integrantes del movimiento, del mismo modo que en el nivel muy inferior de la coordinación relativa las pautas motoras armónicas demuestran ser estables y funcionales. Es posible que el placer de la función, liberado de su función teleonómica, ingrese como factor autónomo en el gran juego en el que nada está fijado salvo las reglas del juego. Es posible que el arte humano haya alcanzado su capacidad de crear lo hasta entonces inexistente por haber liberado su motivación más potente, el placer de la función, de las ataduras de su determinación teleonómica». ${ }^{36}$

Hay una profunda diferencia entre el comportamiento humano y el animal. Para Lorenz esta diferencia no estriba tanto en la racionalidad del comportamiento, puesto que la conducta animal está dirigida certera y nítidamente a sus objetivos, como en la liberación del placer que se obtiene en la conducta, de una determinación teleonómica. Sólo el ser humano juega y disfruta por el mismo juego o disfrute. El animal cuando juega, y cuando disfruta, lo hace para perfeccionar la fluidez, elegancia o minimizar el esfuerzo de sus movimientos. El placer se subordina pues, en la vida animal, a las determinaciones teleonómicas, que el animal recibe filogenéticamente. La conducta animal no puede liberarse de las ataduras que determinan la estructura y la conducta de los miembros de su especie.

${ }^{35}$ Lorenz, K., Fundamentos de la etología, cit., p. 44.

${ }^{36}$ Lorenz. K., Fundamentos de la etología, cit., p. 295. 
El animal que ríe

\section{Conclusiones}

Uno de los textos más sorprendentes que podemos leer en Konrad Lorenz, responde a una experiencia realmente insólita que observó nuestro biólogo, cuando contempló el desconcierto y las dudas de un pez ante dos objetos relacionados con la supervivencia. Uno, la propia comida de la que estaba ávido. Y otro, la supervivencia de la propia cría, a la que protegía, portándola casualmente en su boca.

Si alguna vez he visto "pensar" a un pez, fue en aquella ocasión. Uno se da cuenta de lo que representa para un pez encontrarse en tal conflicto, y comprueba que el animal se comporta exactamente lo mismo que se comportaría un hombre; se encuentra bloqueado por todas partes y permanece quieto sin avanzar ni retroceder. ${ }^{37}$

La cosmovisión de nuestro premio Nobel de Medicina toma su impulso en la filosofía kantiana, y en concreto en el celebérrimo $\S 65$ de la Crítica del Juicio, que trata sobre los organismos vivos. A juicio de Lorenz la filosofía kantiana ha prestado «el servicio más intenso a la finalidad última de todo acontecer orgánico». ${ }^{38}$

Lorenz, siguiendo a Kant, intenta articular la causalidad mecánica con la finalidad que detecta en los organismos. Sendas preguntas «hay que formularlas simultáneamente». ${ }^{39}$ El científico, y Lorenz lo hizo en su labor, puede plantearse legítimamente la pregunta por la finalidad de los sistemas vivientes.

El planteamiento de Hartmann es especialmente prometedor para Lorenz, porque aquel planteaba las preguntas por la finalidad exclusivamente en el campo de la etología, y no por ejemplo en el de la botánica, la inmunología, o los microorganismos. Según Hartmann la finalidad se plantea al considerar (i.) la anticipación del comportamiento a realizar; (ii.) la selección de los medios; (iii.) la realización de esa acción con esos medios. Lorenz, a diferencia de Hartmann extiende la teleonomía, a la vida en todas y cada una de sus manifestaciones.

${ }^{37}$ Lorenz, K., Hablaba con las bestias..., p. 73.

${ }^{38}$ Lorenz, K., Fundamentos de la etología..., p. 45, 47.

${ }^{39}$ Lorenz, K., Fundamentos de la etología..., p. 45. 
Pues bien, según Lorenz, y frente a la idea clásica de una causa final o de teleología, la teleonomía se plantea legítimamente dentro de las acciones de los organismos individualmente considerados. En cambio, es ilegítimo extender la idea de teleología a una, varias o todas las líneas filogenéticas. No hay una orden que guie la evolución en su conjunto. Del mismo modo que el biólogo no tiene un compromiso ontológico con un diseñador inteligente, y eso se constata por los "errores", tampoco ese diseñador ha establecido un orden y una dirección entre los diversos seres vivos considerados evolutivamente.

Por eso el árbol de la vida se parece más a las tortuosas ramificaciones de un gran río en su delta, que al diseño de encauzamiento de un río por un equipo de ingenieros. El curso del río, dirá Lorenz está determinado por millones de influencias causales. Lo mismo sucede con el río de la vida. Ha evolucionado según lo que permitían un número ingente de causas.

La admisión de la validez del concepto de teleonomía lleva a Lorenz a rechazar una evolución completamente azarosa. El azar está domesticado, insiste una y otra vez Lorenz, siguiendo a Eigen, porque la evolución de lo viviente no puede contravenir ninguna de las leyes fundamentales de la física.

\section{Bibliografia}

Dawkins, R. (2004): El relojero ciego. Barcelona: RBA.

Delibes de Castro, M. (1970) «Queríamos ser Konrad Lorenz», en K. Lorenz, Hablaba con las bestias los peces y los pájaros. Barcelona: Tusquets, pp. 9-16.

Dieguez, A. (2013) «La función explicativa de los modelos en biología», Filosofía actual de la biología, Contrastes, (18). doi: 10.24310/Contrastescontrastes.v0i0.1157.

Eigen, M. \& Schuster, R. P. (1979) «A principle of natural self organization», The Hypercycle, (64). doi: 10.1007/BF00450633.

Kalikow, T, J. (1987) «Konrad Lorenz as Evolutionary Epistemologist: The Problem of Intentionality», Naturalistic Epistemology. Boston Studies in the Philosophy of Science, (100). doi: 10.1007/978-94-009-3735-2_8.

Lorenz, K. (1941) «Kant's Doctrine Of The A Priori In The Light Of Contemporary Biology», Learning, development and culture, (121-143). doi: ark:/13960/t64488d56.

Lorenz, K. (1971): Evolución y modificación de la conducta. Madrid: Siglo XXI editores.

Lorenz, K. (2006): Fundamentos de la etología. Estudio comparado de las conductas. Barcelona: Paidós.

Lorenz, K. (2017): Hablaba con las bestias, los peces y los pájaros. Barcelona: Tusquets. 


\section{El animal que ríe}

Monod, J. (2016): El azar y la necesidad. Ensayo sobre la filosofía natural de la biología moderna. Barcelona: Tusquets.

Renzi, M. (2013) «La funcionalidad, si existe, no deriva de un propósito. Una argumentación desde la biomorfodinámica y la evo-devo», Filosofía actual de la biología. Contrastes, (Suplemento XVIII). doi: 10.24310/Contrastescontrastes.v0i0.1164.

Laura Durieux Montoya

laura-durieux-@hotmail.com 